\title{
Non-native populations and global invasion potential of the Indian bullfrog Hoplobatrachus tigerinus: a synthesis for risk-analysis
}

\author{
Nitya Prakash Mohanty (D) Angelica Crottini - Raquel A. Garcia • \\ John Measey
}

Received: 1 October 2019/Accepted: 26 August 2020

(C) Springer Nature Switzerland AG 2020

\begin{abstract}
Invasive amphibians have considerable ecological and socio-economic impact. However, strong taxonomic biases in the existing literature necessitate synthesizing knowledge on emerging invaders. The Indian bullfrog, Hoplobatrachus tigerinus, a large dicroglossid frog (snout to vent length: up to $160 \mathrm{~mm}$ ), is native to the Indian sub-continent. Despite the high likelihood of invasion success for $H$. tigerinus, based on the species' natural history traits and human use, the status of its non-native populations and global invasion potential has not yet been assessed. In this paper, we provide a profile of $H$.
\end{abstract}

Electronic supplementary material The online version of this article (https://doi.org/10.1007/s10530-020-02356-9) contains supplementary material, which is available to authorized users.

N. P. Mohanty $(\bowtie) \cdot$ R. A. Garcia · J. Measey

Centre for Invasion Biology, Department of Botany and

Zoology, Stellenbosch University, Stellenbosch 7602,

South Africa

e-mail: nitya.mohanty@gmail.com

N. P. Mohanty

Andaman Nicobar Environment Team,

Wandoor, South Andaman,

Andaman and Nicobar Islands 744103, India

A. Crottini

CIBIO, Centro de Investigação em Biodiversidade

e Recursos Genéticos, InBIO, Universidade do Porto,

Campus Agrário de Vairão, Rua Padre Armando Quintas,

No 7, 4485-661 Vairão, Portugal tigerinus as an invasive species to aid in risk analyses and management of existing populations. We review the available knowledge on non-native populations of $H$. tigerinus and model its potential distribution in the non-native range and globally; finally, we evaluate its ecological and socio-economic impact using standard impact classification schemes. We confirm successful invasions on the Andaman archipelago and Madagascar. The ensemble species distribution model, with 'good' predictive ability and transferability, predicts tropical regions of the world to be climatically suitable for the species. Considering potential for propagule pressure, we predict the climatically suitable Mascarene Islands, Malaysia and Indonesia, and East Africa to likely be recipients of bridgehead invasions. We assign the species two impact scores: both socio-economic and environmental scores were 'moderate' with 'medium' confidence levels in our assessment. Finally, this synthesis outlines the invasion process of the genus Hoplobatrachus, which is an emerging group of amphibian invaders.

Keywords Amphibian - Madagascar · Andaman Nicobar · Island invasive · Risk-assessment · Impact scoring - Environmental impact classification for Alien Taxa - Socio-economic impact classification of Alien Taxa $\cdot$ Pet trade 


\section{Introduction}

Invasive amphibians have a considerably high environmental and socio-economic impact (Measey et al. 2016; Kumschick et al. 2017; Bacher et al. 2018). Globally, 78 non-native species of amphibians are known to have at least one established or invasive population (Capinha et al. 2017), whereas nearly 100 non-native amphibians could be considered to have established populations, with a level of uncertainty (Kraus 2009; Measey et al. 2016). A recent review of non-native occurrence of amphibians recorded 263 species, including those traded and present in captivity (van Wilgen et al. 2018), forecasting future invasions of many more amphibian species. Introductions of amphibians have accelerated in recent decades (Seebens et al. 2017; Capinha et al. 2017). However, studies on amphibian invasions are heavily taxonbiased, with only three species (Rhinella marina, Lithobates catesbeianus, and Xenopus laevis) responsible for ca. $81 \%$ of all publications on non-native amphibians (van Wilgen et al. 2018). A focus on emerging and unassessed amphibian invaders is therefore necessary.

The Indian bullfrog, Hoplobatrachus tigerinus (Daudin, 1802), a large dicroglossid frog (snout to vent length: up to $160 \mathrm{~mm}$ ), is native to the Indian subcontinent (Dutta 1997). H. tigerinus is consumed regionally and was formerly a part of the international 'frog leg trade' (Abdulali 1985; Oza 1990). Its large body size, association with human-modified landscapes (e.g. paddy fields; Daniels, 2005), and use as a food resource make $H$. tigerinus a likely candidate for human-mediated introduction outside its native range (Tingley et al. 2010; van Wilgen et al. 2018). Further, the species has a high establishment probability due to its fecundity (ca. 6000 eggs per clutch; Allen et al. 2017) and ability to breed successfully in ephemeral pools of human-modified habitats. Human consumption also makes the species likely to be moved locally in the non-native range, thereby exacerbating its spread (Liu et al. 2014). The carnivorous tadpoles of H. tigerinus prey upon larvae of other anurans (Khan 1996; Grosjean et al. 2004), whereas post-metamorphic individuals consume a broad range of invertebrates and small vertebrates (Padhye et al. 2008), making ecological impacts via predation a matter of concern in the non-native range. Despite the high likelihood of invasion success and impact for $H$. tigerinus (see Novoa et al. 2020), the status of its nonnative populations and its global invasion potential have not yet been assessed.

Systematic literature reviews and species distribution modelling have been used to generate global species profiles for several amphibian invaders (e.g. Lithobates catesbeianus, Ficetola et al. 2007a, b; Xenopus laevis, Measey et al. 2012). Such assessments can be particularly useful in understanding consistent patterns of invasion dynamics of the species as well as its similarities to other invasions in terms of pathways, species traits, recipient ecosystems-a phenomenon referred to as "invasion syndromes" (Novoa et al. 2020). Risk assessments rely on published information from prior invasions, covering the species' invasion potential based on species distribution modelling, dispersal pathways, spread rates, potential impact and recommended management action (Kumschick et al. 2019). Potential impacts of species should ideally be recorded using impact classification frameworks, which are particularly useful to assign standardized scores to an invasive species. Based on dietary assessments of adult $H$. tigerinus on the Andaman Islands, an Environmental Impact Classification of Alien Taxa (EICAT; Blackburn et al. 2014) score of 'minor' impact was assigned to the species by Mohanty and Measey (2018). Previously, a global evaluation by Kumschick et al. (2017) had resulted in the same environmental impact score, whereas the species was considered 'data deficient' under SocioEconomic Impact Classification of Alien Taxa (SEICAT; see supporting information in Bacher et al. 2018). However, a reassessment is deemed necessary in the light of new studies on the ecological and socioeconomic impact of the species.

In this paper, we provide a global species profile of the Indian bullfrog, Hoplobatrachus tigerinus, as an invader, to aid in risk assessment and management of existing non-native populations. To this end, we aim to (1) synthesize existing knowledge on invasion status, dispersal pathways and spread, impact, and management action, (2) evaluate the global invasion potential using species distribution models, and (3) update standardized metrics of impact (EICAT and SEICAT) for H. tigerinus based on current knowledge of the species' environmental and socio-economic effects. 


\section{Methods}

Non-native populations

We searched for literature on non-native populations of Hoplobatrachus tigerinus on Google Scholar (September 2018) by employing a combination of key words covering taxonomic variation (including the previous taxonomic combinations 'Rana tigerina' and 'Rana tigrina') and invasion status ('alien', 'introduced', 'non-native', 'exotic', 'non-indigenous' and 'invasive'). We also consulted local researchers and herpetologists, in both native and non-native ranges, for occurrence information where published literature was lacking (Ficetola et al. 2007a). Identified non-native populations were evaluated for their invasion stage (following Blackburn et al. 2011), dispersal pathways (of introduction and secondary transfers), impact (see section 'Impact Scoring' below), and management actions undertaken.

\section{Species distribution modelling}

Species distribution modelling was carried out to determine global climatic suitability for $H$. tigerinus. We collated occurrence data for $H$. tigerinus from three sources: (1) online databases-the Global Biodiversity Information Facility (www.gbif.org), India biodiversity portal (www.indiabiodiversity.org), iNaturalist (www.inaturalist.org), and HerpNET (www.herpnet.org), (2) field observations (AC and NPM unpublished data), and (3) literature records with accurate geographic co-ordinates (point locations of individuals observed). We ensured the quality of occurrence data by only using geo-referenced locations with at least "municipality" level information. Further, we checked if the occurrence points fell within the known 'extent of occurrence' of the species (Padhye et al. 2008). To fill in geographic gaps, we searched for native range records in the literature and citations therein. Sampling bias in occurrence data is an important consideration that may affect model performance and predictions (Merow et al. 2013). As our occurrence records were sourced from a range of data types (museum records, field surveys, and citizen science), we did not expect the data to be inherently biased towards geographical areas with higher humaninfluence. We also visualized the environmental data in the training extent using bivariate plots, overlaid with the presence points, and did not find any strong patterns suggesting environmental sampling bias (Supplementary Information 1 Fig. 1). After removing duplicates (at a resolution of 2.5 arc min), a total of 153 presence points was retained from the native range.

Models can be trained with only native range data when the environmental extent of the non-native range is contained within that of the native range (Gallien et al. 2010) and if native range data are reliable (Hattab et al. 2017). We considered that these two requirements were met in our case. We found the environmental space in the non-native range of $H$. tigerinus to be a subset of its native range (SI 1 Fig. 2). As $H$. tigerinus is a commonly encountered frog with a wide distribution in its native range (Daniels 2005), we considered the collated occurrence data to be of good quality. We also could not assume the non-native populations to have attained equilibrium (Václavik et al. 2012), given their relatively short residence times (Mohanty and Measey 2019a). Finally, we were cognizant of incomplete sampling for $H$. tigerinus on Madagascar. We thus trained the model with native range data only and used data from the non-native range for independent evaluation (see below).

We selected predictors with putative ecological importance for H. tigerinus (e.g. Mellert et al. 2011) based on the species' known ecology and behavior. We also considered known correlates of the distribution of a functionally analogous species, Lithobates catesbeianus (Ficetola et al. 2007b), to inform the selection of environmental predictors. To capture the species' thermal tolerance, we considered two predictors: the maximum temperature of the warmest month and the minimum temperature of the coldest month (following Ficetola et al. 2007b). Adult H. tigerinus are dependent on waterlogged ephemeral pools for breeding and development of larvae (Khan 1996); to model this dependence, we chose mean precipitation of the wettest quarter. Mean precipitation of the driest quarter served as an index for lentic water bodies, which are used by adults to avoid desiccation (Daniels 2005). Human effects are important to consider in species distribution modelling, especially for invasive species (Ficetola et al. 2010; Rödder 2009; Gallardo et al. 2015). The frequent use of human-modified environments by H. tigerinus (Daniels 2005) was accounted for with the Human Influence Index (HII), 
representing a combination of population density, land use, and human accessibility parameters (WCS 2005).

The selected climatic predictors, derived from monthly temperature and rainfall values, were downloaded at a resolution of 2.5 arc minutes from WorldClim version 1 (Hijmans et al. 2005), whereas HII was available at a finer resolution of 30 arc seconds (WCS 2005). To ensure compatibility between these predictor layers, we resampled HII to 2.5 arc minutes by bilinear interpolation, using ArcMap version 10.6.2 (ESRI 2012). For the invaded range, we obtained environmental predictors at 30 arc seconds (Hijmans et al. 2005). After performing pairwise correlation tests for collinearity in predictors (discarded if $r>0.7$ ), we retained all hypothesized predictors but mean precipitation of the driest quarter.

Species distribution modelling was carried out in the $\mathrm{R}$ environment (version 3.4.4; R Core Team 2019) using the package 'biomod2' (Thuiller et al. 2016), designed to perform a range of modelling algorithms and analyze uncertainties. For presence-only species data, pseudo-absence selection should be limited to a meaningful extent that the species could have theoretically sampled over a geological time scale (Barve et al. 2011). In the same geographical area as our study, Tingley et al. (2018) modelled the distribution of the Common Asian toad (Duttaphrynus melanostictus) by limiting the training extent to regions south of the Himalayan mountain range which is likely to limit the dispersal of amphibians. We limited the geographical training extent of our models in the Indian sub-continent to the same region (Fig. 1a). Pseudo-absences were drawn randomly within the training extent, multiple times $(n=1000$, iterations $=5$ ) to reduce sampling bias and weighted to ensure a prevalence of 0.5 (i.e. the weighted sum of presences equals the weighted sum of pseudo-absences). We chose 'random' sampling of pseudoabsences as it generally performs well with most model algorithms, especially regression techniques (see below; Barbet-Massin et al. 2012).

We evaluated the models for predictive performance in the native range and for model transferability to new geographical areas. Evaluation metrics included the Boyce index (Hirzel et al. 2006; values range from -1 to $1 ; 0$ denotes random agreement and values closer to 1 represent good agreement between prediction and data), the Area Under the receiver operating characteristic Curve (AUC; values range from 0 to $1 ; 0.8 \leq$ AUC $<0.9=$ good; $0.9 \leq$ AUC $=$ excellent; Swets 1988), the True Skill Statistic (TSS; Allouche et al. 2006; values range from -1 to 1; 0 denotes a random fit and values closer to 1 represent systematically correct predictions), and sensitivity (or percentage of true positives), particularly important for invasive populations (JiménezValverde et al. 2011). To test predictive performance in the native range, the entire dataset of presence and pseudo-absence points was randomly split to set aside $20 \%$ of points for evaluation, with five-fold validation. Transferability of the model was tested by geographically splitting the presence and pseudo-absence data into four quadrants, with three quadrants used to train the model and the fourth quadrant used to test the model with the Boyce index (spatially-subset k-fold cross validation; Jiménez-Valverde et al. 2011). This process was repeated for all four combinations of training-evaluation quadrants (SI 1 Fig. 3), across three randomly generated sets of pseudo-absences. Finally, independent evaluation of the model was carried out with the Boyce index using occurrence records from the non-native range (Andaman Islands and Madagascar; $\mathrm{n}=55$; at a resolution of 2.5 arc $\min )$.

We used a range of different modelling algorithms because of the known uncertainty arising from algorithm choice (Araújo and New 2007; Garcia et al. 2012). We executed algorithms covering environmental envelope (surface response envelope, SRE), regression (Generalized Linear Model, GLM; Generalized Additive Model, GAM), classification (Classification Tree Analysis, CTA) and machine learning (Generalized Boosting Model, GBM) techniques. Given our aim of predicting potential environmentally suitable regions for $H$. tigerinus occurrence globally, we chose to build simple models to maximize transferability and avoid overfitting (Merow et al. 2014). Therefore, we used a small number of predictors $(n=4)$, employed the biomod 2 default features for each modelling technique (as opposed to making them more complex), and assessed the shape of the response curves. An ensemble modelling approach (Araújo and New 2007) was carried out to generate a final model that combined (median value) all modelling techniques, cross-validations and pseudo-absence runs, while disqualifying the only model (SRE) with AUC below 0.7. 
(a)

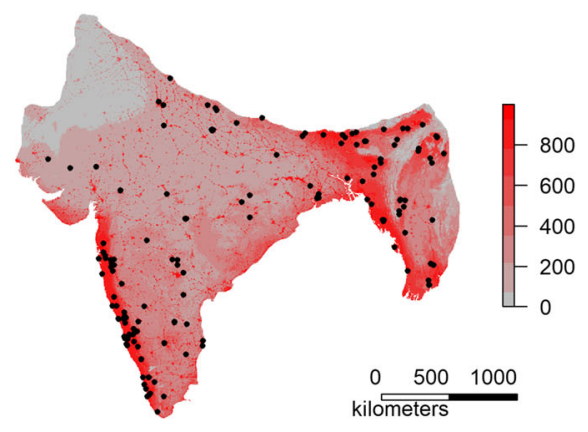

(b)

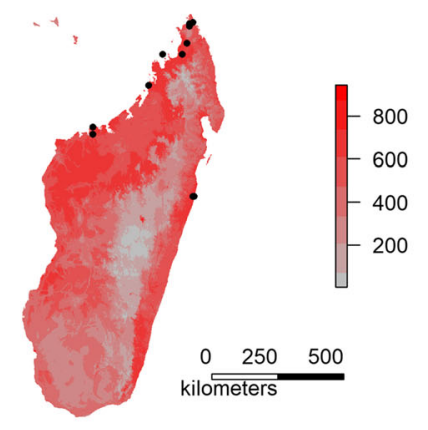

(c)

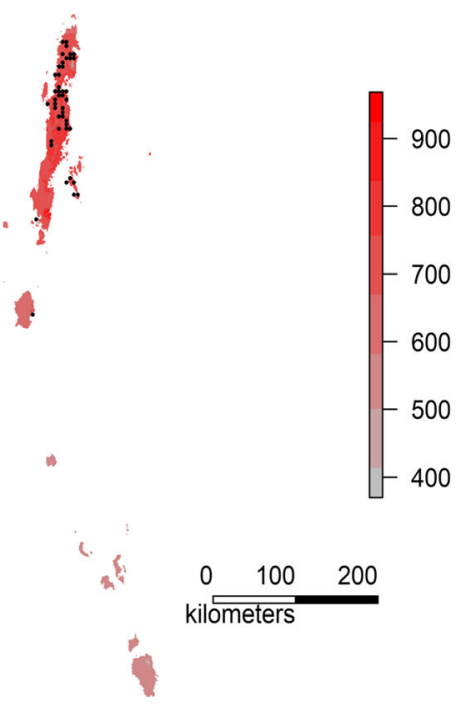

Fig. 1 Predicted environmental suitability of Hoplobatrachus tigerinus in a the native range (Indian subcontinent) and the confirmed invaded areas of $\mathbf{b}$ Madagascar and $\mathbf{c}$ Andaman archipelago, based on ensemble species distribution modelling. Each sub-figure shows the median ensemble projection at 30 arc

To assess uncertainty in projections, we generated coefficient of variation maps (calculated across all included models) for the regions of interest, based on the ensemble model. Correlative species distribution models assume that the training data are representative of conditions to which the models are projected, which may not be valid in the case of biological invasions (Elith et al. 2010). Therefore, extrapolation areas were mapped to explicitly identify grid cells with predictor values falling outside the extent of values used for training the models, where confidence in model outputs would be lower. Finally, we projected the ensemble model globally at the original resolution (2.5 arc $\min$ ) and in the invaded range at a finer resolution of 30 arc second.

\section{Impact scoring}

We scored the invasive Hoplobatrachus tigerinus for impact using literature on non-native populations (see above), based on two impact scoring systems. Our assessments were independent of previous classification scores and their underlying literature. First, we followed the EICAT scheme proposed by Blackburn et al. (2014), supplemented with guidelines by Hawkins et al. (2015). Second, we used the SEICAT scheme as described by Bacher et al. (2018). In both second resolution. Predictors included maximum temperature of the warmest month, minimum temperature of the coldest month, mean rainfall of the wettest quarter, and human influence index (HII). See SI 1 Fig. 6 and Fig. 7 for the associated extrapolation and uncertainty maps

scoring systems, one or more impact mechanisms are identified based on literature (e.g. predation; Table 1); the intensity of each impact mechanism, ranging over five categories, is then assessed. The lowest category in both schemes ('minimal concern') corresponds to no change in fitness of individuals of other native species (EICAT) or human well-being (SEICAT). The highest category ('massive') corresponds to irreversible changes such as local disappearance of a human activity caused by the alien species or changes to ecosystem properties (see Hawkins et al. 2015 and Bacher et al. 2018 for details). A confidence score is assigned to each assessment ('low', 'medium' or 'high') based on the nature and scale of evidence. Finally, the 'maximum recorded impact' based on currently available literature is ascribed to the species (Hawkins et al. 2015).

\section{Results and discussion}

Non-native populations

\section{Andaman Islands}

Hoplobatrachus tigerinus was first reported from two localities on the Andaman archipelago (Mayabunder, 
Table 1 Impact scores (and associated confidence level) of the Indian bullfrog Hoplobatrachus tigerinus in all categories of the 'Environmental Impact Classification of Alien Taxa'
(EICAT) and the relevant category of 'Socio-Economic Impact Classification of Alien Taxa' (SEICAT)

\begin{tabular}{|c|c|c|c|}
\hline Impact mechanism & Score & Confidence & Remarks \\
\hline Competition & $\mathrm{MN}$ & High & $\begin{array}{l}\text { Mohanty and Measey (2018); competition for acoustic niche is } \\
\text { probable }\end{array}$ \\
\hline Predation & MO & Medium & $\begin{array}{l}\text { Mohanty and Measey }(2018,2019 b) \text {; indirect predation of native } \\
\text { species by predator supplementation }\end{array}$ \\
\hline Hybridisation & DD & & $\begin{array}{l}\text { Probable if introduced to regions with congeneric species (e.g. } H \text {. } \\
\text { occipitalis) }\end{array}$ \\
\hline $\begin{array}{l}\text { Transmission of diseases to native } \\
\text { species }\end{array}$ & DD & & Probable chytridiomycosis vector \\
\hline Parasitism & DD & & Unlikely \\
\hline Poisoning/toxicity & DD & & Unlikely \\
\hline Bio-fouling & DD & & Unlikely \\
\hline Grazing/herbivory/browsing & $\mathrm{MN}$ & Medium & Mohanty and Measey (2019b); tadpoles also graze on algae \\
\hline $\begin{array}{l}\text { Chemical, physical, or structural } \\
\text { impact on ecosystems }\end{array}$ & DD & & Unlikely \\
\hline Interaction with other alien species & DD & & $\begin{array}{l}\text { May facilitate survival of larval Duttaphrynus melanostictus on } \\
\text { Madagascar }\end{array}$ \\
\hline $\begin{array}{l}\text { Material and immaterial assets } \\
\text { (SEICAT) }\end{array}$ & MO & Medium & Mohanty and Measey (2019a) \\
\hline
\end{tabular}

$M L$ minimal, $M N$ minor, $M O$ moderate, $M R$ major, $M V$ massive, $D D$ data deficient

Middle Andaman and Wandoor, South Andaman) in 2013, with the view that it was intentionally introduced in 2009-2010 from the Indian mainland (Harikrishnan and Vasudevan 2013). Subsequently, Rangasamy et al. (2014) reported occurrence on two other islands of the archipelago-Neil and Havelock Islands. Using public surveys to retrospectively assess invasion history, Mohanty and Measey (2019a) reported first establishment in 2001, followed by a lag phase of eight to ten years. However, a record of $H$. tigerinus from 1978 from the archipelago still needs verification (Harikrishnan and Vasudevan 2018). After 2009, the population spread to six of the eight major human-inhabited islands of the Andaman archipelago, with established populations occurring in at least 58 of 91 villages by 2017 (see Mohanty and Measey 2019a). Pathways contributing to the invasive spread included propagules as 'contaminants' of fish culture and intentional 'release' for consumption and novelty (Hulme et al. 2008; Mohanty and Measey 2019a). Tadpoles of $H$. tigerinus were likely to be transported accidentally with fish fingerlings, which are used for aquaculture; adult $H$. tigerinus were intentionally released, with frequent human-mediated transfers $\quad(47.48 \pm 11.81 \mathrm{~km}$, range $6.2-188 \mathrm{~km}$; Mohanty and Measey 2019a) within and between islands. Importantly, dispersal hubs (sites that served as the origin of multiple dispersals in the invaded range) were influential in exacerbating spread and could be targeted for management (Mohanty and Measey 2019a). We therefore consider this population to be fully invasive on the Andaman Islands (Category E, Blackburn et al. 2011).

Post-metamorphic H. tigerinus prey upon small vertebrates (including many endemic species of the archipelago), which constitute a majority of its diet by volume, whereas invertebrates are numerically higher (Mohanty and Measey 2018). Significant dietary overlap occurs with Limnonectes spp., indicating a potential for competition (Mohanty and Measey 2018). It is important to note that Limnonectes spp. on the Andaman archipelago may harbor multiple undescribed species (Harikrishnan and Vasudevan 2018) facing competition from H. tigerinus. Economic loss to household-level poultry and aquaculture has also been reported (Mohanty and Measey 2019a). Predation by larval $H$. tigerinus has been documented to cause zero survival of endemic Microhyla 
chakrapanii and Kaloula ghoshi tadpoles (under mesocosm conditions), a mechanism that could lead to population extirpations (Mohanty and Measey 2019b). No management action is in effect for the invasive $H$. tigerinus population on the Andaman Islands, as the species is protected under the Schedule IV of the Indian Wildlife Protection Act (1972) which applies to the entire geopolitical region of India.

\section{Madagascar}

The first published record of $H$. tigerinus on Madagascar comes from Guibé (1953), where the author reported a specimen that was collected by R. Paulian in Mahajanga region, in the northwest of the island (Vences et al. 2003). Guibé identified the specimen as Rana t. tigrina and suggested a 'recent' introduction (Guibé 1953). The taxonomic identity of this specimen was supported by Blommers-Schlösser and Blanc (1991), and a subsequent molecular study confirmed that specimens collected on Madagascar belong to $H$. tigerinus (Kosuch et al. 2001). Guibé (1953) also noted that $H$. tigerinus is common in its native range and is consumed by humans, suggesting that the species might have been intentionally introduced to support the protein intake of local communities (Vences et al. 2003). Another possible reason for the introduction could have been its use as biocontrol of rodents and mosquito larvae (Vences et al. 2003). However, precise information on the introduction event(s) continues to be unclear (Guibé 1953; Kosuch et al. 2001; Vences et al. 2003).

Populations of $H$. tigerinus are widely distributed at low altitude sites in the north and northwest of Madagascar, with confirmed records from the wild at several sites (see SI 2 for detailed list). Recently, $H$. tigerinus has also been reported from Ivoloina and Tamatave, on the eastern coast of Madagascar (AC unpublished data). Overall, the species is expanding its range at low altitudes in the northwest, in the eastern coast and apparently also on the island of Nosy Be (Andreone et al. 2003; Padhye et al. 2008). The species is known to be sold live in city markets of Antananarivo and Toliara in south-west Madagascar (Gardner and Jasper 2009; AC unpublished data) but it is unclear if the species is harvested at these locations or elsewhere. Given the synanthropic nature of this species, it may be useful to conduct public surveys to gain more information on the invasion history, especially in the eastern coast of Madagascar where the species most probably expanded its range in recent years. Such surveys in human-modified areas of Madagascar could reveal a larger distribution than is currently known, as herpetofaunal surveys have mostly focused on natural areas of forests. Based on this spread, we consider this population to be fully invasive on Madagascar (Category E, Blackburn et al. 2011).

Within Madagascar, the live trade of H. tigerinus for human consumption is likely to result in the expansion and establishment of new populations. $H$. tigerinus is among the most common species of amphibians sold as food both in street markets and restaurants of urban centers, such as Antananarivo and Toliara (Glaw and Vences 2007; Jenkins et al. 2008; Gardner and Jasper 2009), and at least in northern Madagascar this species is sourced from the wild rather than being farmed for the food trade (Jenkins et al. 2008). The consumption of this species has become increasingly important, with collection and trade reaching a significant volume (for production of the popular "cuisses de nymphe"). A large number of people are currently involved in this business, including collectors in the field, intermediate traders, restaurants and consumers (Jenkins et al. 2008). As H. tigerinus has been present for a relatively long time on Madagascar, it has proved difficult to disentangle its dispersal pathways. But it is worth noting that there has been little research on the spread and impacts of this invasive population.

No management against the spread and proliferation of this frog on Madagascar is in effect. While harvesting adults might help population control, the food trade has almost certainly helped facilitate introduction and establishment in new locations. In the 1990s, this species was collected intensively in rice paddies of the Marovoay area (northwestern Madagascar), apparently leading to a strong proliferation of rodents (Vences et al. 2003). This incident convinced regional authorities that the species had to be considered beneficial rather than a threat and a communitybased effort to reduce the harvesting was put in place (Vences et al. 2003). However, we lack information to know if this program is still active. 
Maldives and Lakshadweep (Laccadives)

Dutta (1997) recorded introduced H. tigerinus on the Maldive Islands, but recent records confirming establishment and spread are missing. H. tigerinus has also been reported from Minicoy Island in the Lakshadweep archipelago, Arabian Sea (Sinha 1994). Our recent attempts to validate this record through local researchers did not confirm current presence of $H$. tigerinus; the only amphibians reported from both Maldives and Lakshadweep by researchers were of bufonids, most likely Duttaphrynus melanostictus (from photographic ID).

\section{Captive populations}

H. tigerinus populations are present in captivity, intended for farming, in Cuba (Borroto-Páez et al. 2016; Category B1, Blackburn et al. 2011) and Thailand (Timsina 2013; Category B2, Blackburn et al. 2011), with no records of populations occurring in the wild. The species has been recorded in the pet trade (Carpenter et al. 2014), in Brazil (Fonseca et al. 2019) and the USA (Mohanty and Measey 2019c).

Species distribution modelling

The ensemble species distribution model for $H$. tigerinus, reflecting the median across all crossvalidations and pseudo-absence runs, was 'good' in performance in the native range (AUC $=0.89$, range $0.58-0.90 ;$ TSS $=0.66$, range $0.31-0.70$; see SI 1 Fig. 4 for the results for single-models). Sensitivity of the ensemble model was $87.5 \%$, indicating high true positive detection. Model transferability to new geographical areas was high, as indicated by the results of spatially-subset k-fold cross validation (mean Boyce index $=0.65$, range $0.34-0.92$; SI 1 Table 1 ). Independent evaluation of the ensemble model using nonnative range occurrences resulted in Boyce index values of 0.77 for Madagascar and 0.90 for the Andaman Islands, indicating good predictive power. The mean precipitation of wettest quarter had relatively high importance in the ensemble model (21.7\%), followed by HII (19.5\%), maximum temperature of the warmest month $(18.3 \%)$, and minimum temperature of the coldest month (17.3\%). While mean precipitation and HII had sigmoidal relationships with suitability, maximum and minimum temperature had bell-shaped response curves (SI 1 Fig. 5). Overall, extrapolation maps suggested that most high-suitability regions, globally and in the confirmed invaded range (Andaman and Madagascar), had predictor values within the range of the training values, allowing us to place higher confidence in these results (SI 1 Fig. 6). Model uncertainty was similarly low in regions with higher suitability values (SI 1 Fig. 7).

In non-native areas, most regions on the Andaman Islands were predicted as suitable for $H$. tigerinus occurrence, and lowland areas on Madagascar were particularly suitable (Fig. 1). From the perspective of environmental suitability, the population on the Andaman archipelago has the potential to establish in at least two more human inhabited islands hitherto uncolonized (Long and Baratang). On Madagascar, new areas along the east and the west coast were predicted as environmentally suitable for establishment (Fig. 1). Pearson (2015) inferred a similar potential distribution for the invasive population of D. melanostictus on Madagascar, another anuran native to South-East Asia; however, Vences et al. (2017) identified higher suitability mostly along the eastern coast. The predicted range for $H$. tigerinus (Fig. 1) should be considered as a hypothesis to inform further field surveys in the non-native range (Jarnevich et al. 2015).

Globally, our models predicted higher suitability in the tropical parts of Central and South America (including Brazil), Africa, Madagascar, South-East Asia and Australia (Fig. 2). However, this prediction does not necessarily translate into invasion risk. The only regions at risk are those with a potential for introduction through translocation for food or

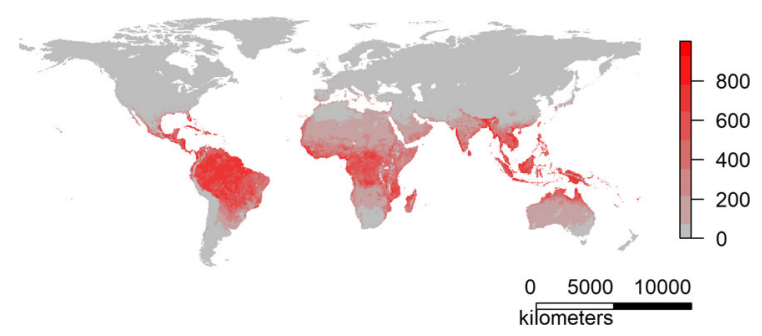

Fig. 2 Global environmental suitability (median ensemble projection) for Hoplobatrachus tigerinus, based on ensemble species distribution modelling for the native range, projected at a resolution of 2.5 arc minutes. See SI 1 Fig. 6 and Fig. 7 for the associated extrapolation and uncertainty maps 
biocontrol, pet trade, and contamination of fish culture (Mohanty and Measey 2019a, c). The species was listed in Appendix II of Convention on International Trade in Endangered Species of Wild Fauna and Flora (CITES; www.cites.org) in 1985, as a result of its harvest for the international 'frog leg trade' (Abdulali 1985; Oza 1990). Due to this listing, its export (and not import) requires permissions from relevant authorities. Permission is conditional on the assessment if such trade will be detrimental to the survival of the species in the wild. Further, any collection or export of $H$. tigerinus for commercial purposes is prohibited under the Indian Wildlife Protection Act. However, unintentional introductions, within-country trade, and illegal trade are likely to go undocumented. Under the current trade climate, intentional release is highly likely in the Nicobar archipelago, although environmental suitability is low. Similarly, bridgehead introductions are possible to the climatically suitable regions of Malaysia, Indonesia, Mascarene Islands and eastern Africa. As new occurrence data in the invaded range become available, future modelling efforts for this species should quantify niche dynamics during the invasion process and include both the native and non-native ranges in the training step.

\section{Impact scoring}

Based on the experimental documentation of $H$. tigerinus impact on tadpoles of the endemic Microhyla chakrapanii and Kaloula ghoshi on the Andaman archipelago (Mohanty and Measey 2019b), we assigned a score of 'moderate' environmental impact to the species, with a 'medium' confidence score due to the limited scale of the experiment (Table 1). Interview data from key informants (farmers, plantation workers, and pond owners; see Mohanty and Measey 2019a) record population declines in native anurans; we scored this environmental impact as 'moderate' with 'low' confidence due to the inferred nature of the information (Table 1). Socio-economic impact was also scored as 'moderate' based on the same set of key informant interviews, which recorded cessation of poultry keeping by many households, due to predation by $H$. tigerinus (Table 1 ). We assigned a confidence score of 'medium' due to possible ambiguity given that the data resulted from semi-structured questionnaire surveys, lacking a directed question at abandonment of activity (Mohanty and Measey 2019a). These impact scores were based solely on the invasive population on the Andaman archipelago, in the absence of published information on impacts on Madagascar.

Based on the evaluation of non-native populations, we provide a species summary of $H$. tigerinus describing key aspects of its invasion process, including dispersal pathways, environmental suitability, and impact (Table 2). Apart from known impact mechanisms for $H$. tigerinus, impacts of other invasive large Ranoid frogs (superfamily Ranoidea; Novoa et al. 2020) indicate the possibility of competition for acoustic niche (Both and Grant 2012), disease transmission (Mutnale et al. 2018), facilitative interaction with non-native species (Adams et al. 2003). Indirect exacerbation of predation on native species by predator supplementation (Woolbright et al. 2006), and hybridization (Dufresnes et al. 2015), are also probable mechanisms that require future evaluation (Table 1).

\section{Generalities with other taxa}

The five species that currently constitute the genus Hoplobatrachus (H. tigerinus, H. rugulosus-syn. H. chinensis, H. crassus, H. occipitalis, H. litoralis; Frost, 2019) share traits that are likely to make them part of an "invasion syndrome" (e.g. Novoa et al. 2020). These large-bodied, semi-aquatic anurans with high fecundity tend to thrive in human-modified environments. Apart from these life-history traits, which promote invasions in amphibians, at least four species are used for human consumption (Carpenter et al. 2014; Mohneke et al. 2009) and three are traded as pets, including the likely illegal trade of $H$. tigerinus due to its CITES listing (Mohanty and Measey 2019c). Hoplobatrachus rugulosus (syn. H. chinensis), the only other congener with known introductions, has invasive populations on Philippines and Borneo (Pili et al. 2019); the species also shares dispersal pathways with $H$. tigerinus (release for food, contaminant of fish fingerlings; Pili et al. 2019).

The carnivorous nature of tadpoles in the genus Hoplobatrachus is hypothesized to have facilitated their historical colonization of arid environments where ponds could be ephemeral (Grosjean et al. 2004). This carnivorous behavior, which drastically reduces survival of co-occurring native tadpoles (Mohanty and Measey 2019b; Table 1), could 
Table 2 Summary of invasion dynamics of the Indian bullfrog Hoplobatrachus tigerinus with supporting literature and remarks

\begin{tabular}{|c|c|c|c|}
\hline & Description & Literature & Remarks \\
\hline Native range & Indian sub-continent & Dutta (1997) & \\
\hline $\begin{array}{l}\text { Non-native } \\
\text { range }\end{array}$ & Andaman Islands, Madagascar & $\begin{array}{l}\text { Mohanty and Measey (2019a) } \\
\text { and Vences et al. (2003); } \\
\text { see SI } 2\end{array}$ & $\begin{array}{l}\text { Distribution on Madagascar } \\
\text { updated in current study }\end{array}$ \\
\hline $\begin{array}{l}\text { Unaided } \\
\text { pathways }\end{array}$ & $\begin{array}{l}\text { Contamination of freshwater fish culture by } \\
\text { tadpoles }\end{array}$ & Mohanty and Measey (2019a) & $\begin{array}{l}\text { Likely to benefit from farm dams } \\
\text { [e.g. Govindarajulu et al. } \\
\text { (2005) and Davies et al. } \\
(2013)]\end{array}$ \\
\hline $\begin{array}{l}\text { Aided } \\
\text { pathways }\end{array}$ & $\begin{array}{l}\text { Intentional release for consumption and } \\
\text { biocontrol }\end{array}$ & $\begin{array}{l}\text { Harikrishnan and Vasudevan } \\
\text { (2013), Mohanty and } \\
\text { Measey (2019a) and Guibé } \\
\text { (1953) }\end{array}$ & \\
\hline $\begin{array}{l}\text { Environmental } \\
\text { predictors }\end{array}$ & $\begin{array}{l}\text { Maximum temperature of warmest month, } \\
\text { Minimum temperature of the coldest month, } \\
\text { Human influence index, Mean rainfall of } \\
\text { wettest quarter }\end{array}$ & Current study & \\
\hline $\begin{array}{l}\text { Environmental } \\
\text { impact }\end{array}$ & $\begin{array}{l}\text { Predation and competition with anurans by } \\
\text { adults; inter-specific predation by } \\
\text { carnivorous tadpoles }\end{array}$ & $\begin{array}{l}\text { Mohanty and Measey } \\
(2018,2019 b)\end{array}$ & $\begin{array}{l}\text { Population level declines of } \\
\text { native anurans likely }\end{array}$ \\
\hline $\begin{array}{l}\text { Socio- } \\
\text { economic } \\
\text { impact }\end{array}$ & Predation of poultry and fish stocks by adults & Mohanty and Measey (2019a) & $\begin{array}{l}\text { May lead to reduction and } \\
\text { ceasing of poultry keeping }\end{array}$ \\
\hline
\end{tabular}

influence their invasion success by limiting competition. Apart from the predatory impact of the larval stage, adults of the genus may impact native biodiversity similarly to $H$. tigerinus (e.g. predation of native vertebrates, Table 1; Hirschfeld and Rödel 2011; Pili et al. 2019). Similarities in the invasion process of Hoplobatrachus to the well-studied model species Lithobates catesbeianus (130 publications on its non-native populations; Ficetola et al. 2007a; van Wilgen et al. 2018) belonging to the same "invasion syndrome", should be leveraged to frame hypotheses and inform management (Novoa et al. 2020).

\section{Conclusion}

Non-native populations of $H$. tigerinus are likely to spread to climatically suitable regions that have potential for live trade (consumption and pet trade) and contamination of fish culture. Regions at higher risk for incursions include the Nicobar archipelago, Malaysia, Indonesia, Mascarene Islands and eastern Africa, due to likelihood for bridgehead introductions and climatic suitability. Implementation of biosecurity measurements (such as the screening of traded goods at seaports and airports) is strongly recommended, along with monitoring of illegal pet trade for emergence of $H$. tigerinus (and other species in this genus) as a species of choice. Risk assessments of the species should be informed by the aspect of human-use which is likely to enhance the likelihood of establishment and spread.

Acknowledgements This research was supported by the DSINRF Centre of Excellence for Invasion Biology (CIB). We would like to thank: the Department of Environment and Forests, Andaman and Nicobar Islands, for granting permits (\#CWLW/WL/134/350); the Inlaks Shivdasani FoundationRavi Sankaran Fellowship Programme and the Rufford Small Grants (\#20818-2) for funding. Portuguese National Funds through FCT (Fundação para a Ciência e a Tecnologia) supported the Investigador FCT grant to AC (IF/ 00209/2014). NPM would like to thank Alex Rebelo and Mohlamatsane Mokhlatla for valuable inputs on the species distribution models. We extend our thanks to Karen Freeman, Virgina Rodriguez Ponga, staff of Madagascar Fauna and Flora Group in Tamatave, Abhijit Das, Rohan Arthur, Achille Raselimanana for sharing information and providing valuable inputs. Constructive criticism from three anonymous reviewers and the handling editor (Craig Guyer) helped improve the manuscript. 


\section{References}

Abdulali H (1985) On the export of frog legs from India. J Bombay Nat Hist Soc 82(2):347-375

Allen WL, Street SE, Capellini I (2017) Fast life history traits promote invasion success in amphibians and reptiles. Ecol Lett 20(2):222-230

Allouche O, Tsoar A, Kadmon R (2006) Assessing the accuracy of species distribution models: prevalence, kappa and the true skill statistic (TSS). J Appl Ecol 43:1223-1232. https://doi.org/10.1111/j.1365-2664.2006.01214.x

Andreone F, Glaw F, Nussbaum RA, Raxworthy CJ, Vences M, Randrianirina JE (2003) The amphibians and reptiles of Nosy Be (NW Madagascar) and nearby islands: a case study of diversity and conservation of an insular fauna. J Nat Hist 37:2119-2149

Araújo MB, New M (2007) Ensemble forecasting of species distributions. Trends Ecol Evol 22(1):42-47

Bacher S, Blackburn TM, Essl F et al (2018) Socio-economic impact classification of alien taxa (SEICAT). Methods Ecol Evol 9(1):159-168

Barbet-Massin M, Jiguet F, Albert CH, Thuiller W (2012) Selecting pseudo-absences for species distribution models: How, where and how many? Methods Ecol Evol 3(2):327-338

Barve N, Barve V, Jiménez-Valverde A et al (2011) The crucial role of the accessible area in ecological niche modeling and species distribution modeling. Ecol Model 222:1810-1819. https://doi.org/10.1016/j.ecolmodel.2011. 02.011

Blackburn TM, Pyšek P, Bacher S et al (2011) A proposed unified framework for biological invasions. Trends Ecol Evol 26(7):333-339

Blackburn TM, Essl F, Evans T et al (2014) A unified classification of alien species based on the magnitude of their environmental impacts. PLoS Biol. https://doi.org/10. 1371/journal.pbio.1001850

Borroto-Páez R, Bosch RA, Fabres BA, García OA (2016) Introduced amphibians and reptiles in the Cuban archipelago. Herpetol Conserv Biol 10:985-1012

Both C, Grant T (2012) Biological invasions and the acoustic niche: the effect of bullfrog calls on the acoustic signals of white-banded tree frogs. Biol Lett 8:714-716. https://doi. org/10.1098/rsbl.2012.0412

Capinha C, Seebens H, Cassey P et al (2017) Diversity, biogeography and the global flows of alien amphibians and reptiles. Divers Distrib 23:1313-1322. https://doi.org/10. 1111/ddi.12617

Carpenter AI, Andreone F, Moore RD, Griffiths RA (2014) A review of the international trade in amphibians: the types, levels and dynamics of trade in CITES-listed species. Oryx 48:565-574. https://doi.org/10.1017/S0030605312001627

Dufresnes C, Dubey S, Ghali K, Canestrelli D, Perrin N (2015) Introgressive hybridization of threatened European tree frogs (Hyla arborea) by introduced $H$. intermedia in Western Switzerland. Conserv Genet 16(6):1507-1513

Dutta SK (1997) Amphibians of India and Sri Lanka: checklist and bibliography. Odyssey Publishing House, San Diego

Elith J, Kearney M, Phillips S (2010) The art of modelling range-shifting species. Methods Ecol Evol 1(4):330-342
Environmental Systems Research Institute (ESRI) (2012) ArcGIS Release 10.3.1. Redlands, CA

Ficetola GF, Coïc C, Detaint M et al (2007a) Pattern of distribution of the American bullfrog Rana catesbeiana in Europe. Biol Invasions 9:767-772. https://doi.org/10. 1007/s10530-006-9080-y

Ficetola GF, Thuiller W, Miaud C (2007b) Prediction and validation of the potential global distribution of a problematic alien invasive species: the American bullfrog. Divers Distrib 13:476-485. https://doi.org/10.1111/j.1472-4642. 2007.00377.x

Ficetola GF, Maiorano L, Falcucci A et al (2010) Knowing the past to predict the future: land-use change and the distribution of invasive bullfrogs. Glob Chang Biol 16:528-537. https://doi.org/10.1111/j.1365-2486.2009.01957.x

Fonseca É, Both C, Cechin SZ (2019) Introduction pathways and socio-economic variables drive the distribution of alien amphibians and reptiles in a megadiverse country. Divers Distrib 25:1130-1141. https://doi.org/10.1111/ddi.12920

Gallardo B, Zieritz A, Aldridge DC (2015) The importance of the human footprint in shaping the global distribution of terrestrial, freshwater and marine invaders. PLoS ONE 10:1-17. https://doi.org/10.1371/journal.pone.0125801

Gallien L, Münkemüller T, Albert CH, Boulangeat I, Thuiller W (2010) Predicting potential distributions of invasive species: Where to go from here? Divers Distrib 16(3):331-342

Garcia RA, Burgess ND, Cabeza M, Rahbek C, Araújo MB (2012) Exploring consensus in 21st century projections of climatically suitable areas for African vertebrates. Global Change Biol 18(4):1253-1269

Gardner C, Jasper L (2009) The urban herpetofauna of Toliara, Southwest Madagascar. Herpetol Notes 2:239-242

Glaw F, Vences M (2007) A field guide to the amphibians and reptiles of Madagascar. ISBN-13: 9783929449037

Grosjean S, Vences M, Dubois A (2004) Evolutionary significance of oral morphology in the carnivorous tadpoles of tiger frogs, genus Hoplobatrachus (Ranidae). Biol J Linn Soc 81:171-181. https://doi.org/10.1111/j.1095-8312. 2003.00272.x

Guibé J (1953) Au sujet de l'introduction de Rana tigrine tigerina Daudin à Madagascar. Nat Malgache 5:241-242

Harikrishnan S, Vasudevan K (2013) Recent introduction and spread of Indian bullfrog Hoplobatrachus tigerinus (Daudin, 1802) into the Andaman Islands. Aliens 33:42-43

Harikrishnan S, Vasudevan K (2018) Amphibians of the Andaman \& Nicobar Islands: distribution, natural history, and notes on taxonomy. Alytes 36:238-265

Hattab T, Garzón-López CX, Ewald M et al (2017) A unified framework to model the potential and realized distributions of invasive species within the invaded range. Divers Distrib 23(7):806-819

Hawkins CL, Bacher S, Essl F et al (2015) Framework and guidelines for implementing the proposed IUCN Environmental Impact Classification for Alien Taxa (EICAT). Divers Distrib 21:1360-1363. https://doi.org/10.1111/ddi. 12379

Hijmans RJ, Cameron SE, Parra JL, Jones PG, Jarvis A (2005) Very high resolution interpolated climate surfaces for global land areas. Int J Climatol 25:1965-1978 
Hirschfeld M, Rödel MO (2011) The diet of the African Tiger Frog, Hoplobatrachus occipitalis, in northern Benin. Salamandra 47:125-132

Hirzel AH, Le Lay G, Helfer V et al (2006) Evaluating the ability of habitat suitability models to predict species presences. Ecol Model 199:142-152. https://doi.org/10. 1016/j.ecolmodel.2006.05.017

Hoplobatrachus tigerinus (Daudin, 1802) in GBIF Secretariat (2018) GBIF Backbone Taxonomy. Checklist dataset. https://doi.org/10.15468/39omei. Accessed via GBIF.org on 2018-09-10

Jarnevich CS, Stohlgren TJ, Kumar S, Morisette JT, Holcombe TR (2015) Caveats for correlative species distribution modeling. Ecol Inform 29:6-15

Jenkins RKB, Andrianasolonjatovo MN, Freeman K, Rabearivelo A, Rampilimanana RL, Randrianavelona R (2008) The exploitation of amphibians for food in Madagascar. In: Andreone F (ed) A conservation strategy for the amphibians of madagascar-monografie XLV. Museo Regionale di Scienze Naturali, Torino, pp 343-356

Jiménez-Valverde A, Peterson AT, Soberón J et al (2011) Use of niche models in invasive species risk assessments. Biol Invasions 13:2785-2797. https://doi.org/10.1007/s10530011-9963-4

Khan M (1996) The oropharyngeal morphology and feeding habits of tadpole of Tiger Frog Rana tigerina Daudin. Russ J Herpetol 3:163-171

Kosuch J, Vences M, Dubois A et al (2001) Out of Asia: mitochondrial DNA evidence for an oriental origin of tiger frogs, genus Hoplobatrachus. Mol Phylogenet Evol 21:398-407. https://doi.org/10.1006/mpev.2001.1034

Kraus F (2009) Alien reptiles and amphibians: a scientific compendium and analysis, vol 4. Springer, Berlin

Kumschick S, Wilson JR, Foxcroft LC Framework and guidelines for conducting risk analyses for Alien Species. https:// doi.org/10.20944/preprints201811.0551.v1

Kumschick S, Vimercati G, de Villiers FA et al (2017) Impact assessment with different scoring tools: How well do alien amphibian assessments match? NeoBiota 33:53-66. https://doi.org/10.3897/neobiota.33.10376

Liu X, Li X, Liu Z et al (2014) Congener diversity, topographic heterogeneity and human-assisted dispersal predict spread rates of alien herpetofauna at a global scale. Ecol Lett 17:821-829. https://doi.org/10.1111/ele.12286

Measey GJ, Rödder D, Green SL et al (2012) Ongoing invasions of the African clawed frog, Xenopus laevis: a global review. Biol Invasions 14:2255-2270. https://doi.org/10. 1007/s10530-012-0227-8

Measey GJ, Vimercati G, de Villiers FA et al (2016) A global assessment of alien amphibian impacts in a formal framework. Divers Distrib 22:970-981. https://doi.org/10.1111/ ddi. 12462

Mellert KH, Fensterer V, Küchenhoff H et al (2011) Hypothesisdriven species distribution models for tree species in the Bavarian Alps. J Veg Sci 22:635-646. https://doi.org/10. 1111/j.1654-1103.2011.01274.x

Merow C, Smith MJ, Silander JA (2013) A practical guide to MaxEnt for modeling species' distributions: what it does, and why inputs and settings matter. Ecography 36:1058-1069. https://doi.org/10.1111/j.1600-0587.2013. 07872.x
Merow C, Smith MJ, Edwards TC et al (2014) What do we gain from simplicity versus complexity in species distribution models? Ecography 37:1267-1281. https://doi.org/10. 1111/ecog.00845

Mohanty NP, Measey J (2018) What's for dinner? Diet and potential trophic impact of an invasive anuran Hoplobatrachus tigerinus on the Andaman archipelago. PeerJ 6:e5698. https://doi.org/10.7717/peerj.5698

Mohanty NP, Measey J (2019a) Reconstructing biological invasions using public surveys: a new approach to retrospectively assess spatio-temporal changes in invasive spread. Biol Invasions 21:467-480. https://doi.org/10. 1007/s10530-018-1839-4

Mohanty NP, Measey J (2019b) No survival of native larval frogs in the presence of invasive Indian bullfrog Hoplobatrachus tigerinus tadpoles. Biol Invasions 21:2281-2286. https://doi.org/10.1007/s10530-01901985-z

Mohanty NP, Measey J (2019c) The global pet trade in amphibians: species traits, taxonomic bias, and future directions. Biodivers Conserv 28(14):3915-3923. https:// doi.org/10.1007/s10531-019-01857-x

Mohneke M, Onadeko AB, Rödel MO (2009) Exploitation of frogs - a review with a focus on West Africa. Salamandra 45:193-202

Mutnale MC, Anand S, Eluvathingal LM, Roy JK, Reddy GS, Vasudevan K (2018) Enzootic frog pathogen Batrachochytrium dendrobatidis in Asian tropics reveals high ITS haplotype diversity and low prevalence. Scientific Reports 8(1):10125

Novoa A, Richardson DM, Pyšek P et al (2020) Invasion syndromes: a systematic approach for predicting biological invasions and facilitating effective management. Biol Invasions 22:1801-1820. https://doi.org/10.1007/s10530020-02220-w

Oza GM (1990) Ecological effects of the frog's legs trade. Environmentalist 10:39-42. https://doi.org/10.1007/ BF02239556

Padhye A, Manamendra-Arachchi K, deSilva A, Dutta S, Kumar Shrestha T, Bordoloi S, Papenfuss T, Anderson S, Kuzmin S, Khan MS, Nussbaum R (2008) Hoplobatrachus tigerinus: The IUCN Red List of Threatened Species. http:// dx.doi.org/10.2305/ IUCN.UK.2008.RLTS.T58301A11760496.en

Pearson RG (2015) Asian common toads in Madagascar: an urgent effort to inform surveys and eradication efforts. Glob Chang Biol 21:9. https://doi.org/10.1111/gcb.12693

Pili AN, Sy EY, Diesmos MLL, Diesmos AC (2019) Island hopping in a biodiversity hotspot archipelago: reconstructed invasion history and updated status and distribution of Alien Frogs in the Philippines. Pac Sci 73:321-343. https://doi.org/10.2984/73.3.2

R Core Team (2019) R: a language and environment for statistical computing. R Core Team, Vienna

Rangasamy V, Chandra K, Raghunathan C, Venkataraman K (2014) Amphibians and reptiles in Andaman and Nicobar Islands: diversity and distribution. In: Souvenir: Island Biodiversity, Uttar Pradesh State Biodiversity Board, pp 124-130

Rödder D (2009) Human footprint, facilitated jump dispersal, and the potential distribution of the invasive 
Eleutherodactylus johnstonei Barbour 1914 (Anura Eleutherodactylidae). Trop Zool 22:205-217

Seebens H, Blackburn TM, Dyer EE et al (2017) No saturation in the accumulation of alien species worldwide. Nat Commun 8:1-9. https://doi.org/10.1038/ncomms14435

Sinha B (1994) Geo-economic survey of Lakshadweep. Concept Publishing Company, Delhi

Thuiller W, Georges D, Engler R, Breiner F (2016) biomod2: Ensemble platform for species distribution modeling. $\mathrm{R}$ package version 3.3-7

Timsina TP (2013) Mass production of frog through induced breeding and growth in laboratory and field condition-the case of Indian bullfrog (Rana tigerina). J Indian Res 1(4):89-94

Tingley R, Romagosa CM, Kraus F et al (2010) The frog filter: amphibian introduction bias driven by taxonomy, body size and biogeography. Glob Ecol Biogeogr 19:496-503. https://doi.org/10.1111/j.1466-8238.2010.00530.x

Tingley R, García-Díaz P, Arantes CRR, Cassey P (2018) Integrating transport pressure data and species distribution models to estimate invasion risk for alien stowaways. Ecography 41:635-646. https://doi.org/10.1111/ecog. 02841

Van Wilgen NJ, Gillespie MS, Richardson DM, Measey J (2018) A taxonomically and geographically constrained information base limits non-native reptile and amphibian risk assessment: a systematic review. PeerJ 2018:1-25. https://doi.org/10.7717/peerj.5850
Vences M, Raselimanana AP, Glaw F (2003) Ranidae; Hoplobatrachus, Indian Tiger Frog. In: M. Goodman S, Benstead JP (eds) The natural history of Madagascar. The University of Chicago Press, Chicago and London, pp 926-927

Vences M, Brown J, Lathrop A et al (2017) Tracing a toad invasion: lack of mitochondrial DNA variation, haplotype origins, and potential distribution of introduced Duttaphrynus melanostictus in Madagascar. Amphibia-Reptilia 38(2):197-207

Wildlife Conservation Society-WCS, and Center for International Earth Science Information Network-CIESINColumbia University (2005) Last of the Wild Project, Version 2, 2005 (LWP-2): Global Human Influence Index (HII) Dataset (Geographic). Palisades, NY: NASA Socioeconomic Data and Applications Center (SEDAC). https://doi.org/10.7927/H4BP00QC

Woolbright LL, Hara AH, Jacobsen CM et al (2006) Population densities of the Coquí, Eleutherodactylus coqui (Anura: Leptodactylidae) in Newly Invaded Hawaii and in Native Puerto Rico. J Herpetol 40:122-126. https://doi.org/10. 1670/79-05w.1

Publisher's Note Springer Nature remains neutral with regard to jurisdictional claims in published maps and institutional affiliations. 